\title{
Effects of oral carbohydrate with amino acid solution on the metabolic status of patients in the preoperative period: a randomized, prospective clinical trial
}

\author{
Rie Tsutsumi ${ }^{1}$ Nami Kakuta ${ }^{2}$ Takako Kadota ${ }^{2}$ Takuro Oyama ${ }^{2}$. \\ Katsuyoshi Kume ${ }^{2} \cdot$ Eisuke Hamaguchi $^{2}$ Noriko $\mathrm{Niki}^{2} \cdot \mathrm{Katsuya} \mathrm{Tanaka}^{2}$ • \\ Yasuo M. Tsutsumi ${ }^{2}$
}

Received: 18 January 2016 / Accepted: 10 July 2016 / Published online: 20 July 2016

(C) The Author(s) 2016. This article is published with open access at Springerlink.com

\begin{abstract}
Objective Enhanced recovery after surgery is increasingly desired nowadays, and preoperative nutrient intake may be beneficial for this purpose. In this study, we investigated whether the intake of preoperative carbohydrate with amino acid (ONS) solution can improve starvation status and lipid catabolism before the induction of anesthesia.

Methods This randomized, prospective clinical trial included 24 patients who were divided into two groups before surgery under general anesthesia: a control group, comprising patients who fasted after their last meal the day before surgery (permitted to drink only water), and an ONS group, comprising patients who consumed ONS solution $2 \mathrm{~h}$ before surgery. Biochemical markers, the respiratory quotient, and psychosomatic scores were assessed at the initiation of anesthesia.

Results Compared with the control group, the ONS group showed significantly lower serum free fatty acid levels [control group: $828(729,1004) \mu \mathrm{Eq} / \mathrm{L}$, ONS group: 479 $(408,610) \mu \mathrm{Eq} / \mathrm{L}, P=0.0002$, median $(25$ th, 75 th percentile)] and total ketone bodies [control group: 119 (68, 440) $\mu \mathrm{mol} / \mathrm{L}$, ONS group: 40 [27, 64] $\mu \mathrm{mol} / \mathrm{L}, P=0.037]$. In addition, analysis using the Visual Analog Scale showed higher preoperative scores for anxiety, hunger, and thirst for
\end{abstract}

R. Tsutsumi and N. Kakuta contributed equally to this work.

Yasuo M. Tsutsumi

tsutsumi@tokushima-u.ac.jp

1 Department of Nutrition, Tokushima University, Tokushima, Japan

2 Department of Anesthesiology, Tokushima University, Tokushima, Japan the control group, with no differences in any other measure of subjective well-being between groups.

Conclusions The results of this study suggest that preoperative ONS intake improves lipid catabolism and starvation status before the induction of anesthesia. Furthermore, it can provide better preoperative mental health compared with complete fasting.

Keywords Enhanced recovery after surgery $\cdot$ Preoperative carbohydrate - Quality of life · Surgical outcomes ·

Nutritional status

\section{Introduction}

Enhanced recovery after surgery (ERAS) represents a multimodal approach to improving the outcomes of medical treatment and care [1]. Preoperative intake of oral carbohydrates for ERAS has resulted in some benefits [2, 3]. In patients undergoing surgery, the intake of oral carbohydrates the night before surgery or $2 \mathrm{~h}$ before anesthesia was found to decrease postoperative insulin resistance, with a slight decrease in insulin-stimulated glucose disposal [4]. Carbohydrate intake also decreases preoperative discomfort, such as thirst, hunger, and anxiety [5, 6], and postoperative discomfort, as demonstrated in colorectal patients, in addition to decreasing the length of postoperative hospital stay and accelerating the return of gastrointestinal function and grip strength [2]. However, some studies showed that preoperative carbohydrate intake did not decrease the length of hospital stay or improve insulin resistance [7-9]. Therefore, it remains unclear whether preoperative carbohydrate intake is beneficial to patients.

There are some clinical reports of the benefit of carbohydrate loading before surgery using $12.6 \%$ carbohydrates 
Fig. 1 Study protocol. $R Q$ respiratory quotient, $E E$ energy expenditure, $O N S$ oral nutritional supplement

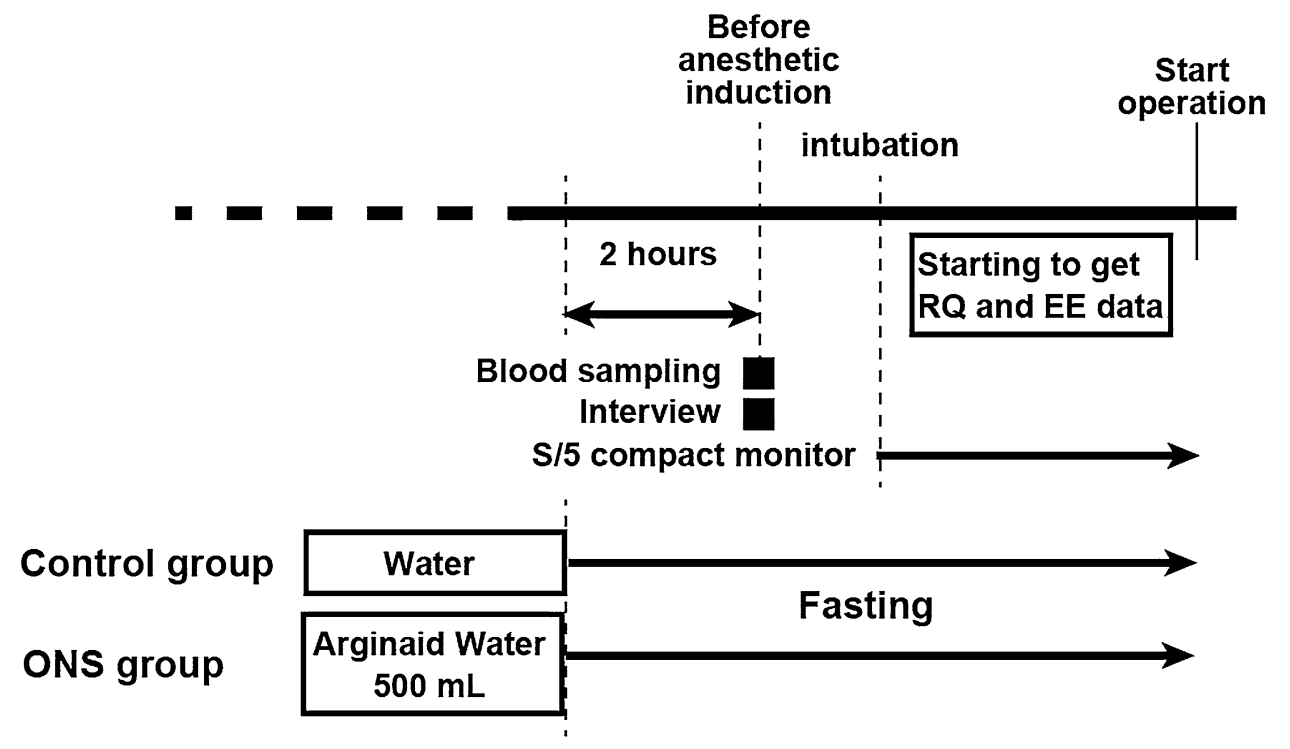

$[10,11]$. However, we typically use $18 \%$ carbohydrate drink with amino acid, instead of beverages containing $12.6 \%$ carbohydrates which are not available in Japan [12-15]. Although the effects of drinks containing $18 \%$ carbohydrates and amino acid [oral nutritional supplement (ONS)] on insulin sensitivity and glucose metabolism have been evaluated [15], their influence on lipid or protein catabolism and energy intake/expenditure before surgery remains unclear. In addition, studies on ERAS interventions followed a multimodal enhanced protocol, and it is unclear whether this protocol included any carbohydrate/protein-based intervention [1]. Therefore, the primary objective of this study was to determine whether the preoperative intake of ONS solution can improve the starvation status and lipid catabolism before the induction of anesthesia.

\section{Materials and methods}

\section{Patients and study protocol}

This study was approved by the Human Research Ethics Committee of the Tokushima University and Sikoku Central Hospital and was registered in a clinical trials database (UMIN000013778). Written informed consent was obtained from all patients, and the study was conducted in accordance with the principles outlined in the Declaration of Helsinki.

Inclusion criteria were established: ages were between 20 and 90 years, the patient was undergoing minor surgery under general anesthesia, and had an American Society of Anesthesiologists (ASA) physical status (PS) of I to III. Obese [body mass index (BMI) $>30 \mathrm{~kg} / \mathrm{m}^{2}$ ] and emaciated
Table 1 Major nutrients in carbohydrate formula composition

\begin{tabular}{ll}
\hline Nutrients & Arginaid water $100 \mathrm{~mL}$ \\
\hline Calories (kcal) & 80 \\
Arginine (g) & 2.0 \\
CHO (g) & 18 \\
Fat (g) & 0 \\
Sodium (mg) & 0 \\
Phosphate (mg) & 140 \\
Zinc (mg) & \\
Manganese (mg) & 0 \\
Copper (mg) & 0.8 \\
Osmotic pressure (mOsm/L) & $560-580$ \\
\hline
\end{tabular}

(BMI $<17 \mathrm{~kg} / \mathrm{m}^{2}$ ) patients and patients with diabetes were excluded.

To ensure blinding of the investigators, a statistician not involved in the clinical study generated the randomization schedule using computer-generated distribution (QuickCalcs, GraphPad Inc., La Jolla, CA, USA). On the day before surgery, the 24 patients were randomized to one of two groups (Fig. 1) and the primary anesthesiologist supplied ONS to the patients to blind the anesthesia team: a control group, comprising 12 patients who fasted after 21:00 on the day before surgery (permitted to drink only water), and an ONS group, comprising 12 patients who received $500 \mathrm{~mL}$ of ONS (Arginaid Water ${ }^{\circledR}$; Nestle Japan, Kobe, Japan) $2 \mathrm{~h}$ before surgery. The nutrient profiles of the carbohydrate drinks are shown in Table 1.

No patient was premedicated. Upon arrival in the operating room, a 20G catheter was inserted into the left or right forearm of each patient and bicarbonate Ringer's solution was infused for $1 \mathrm{~h}$. General anesthesia was induced and 
the patients were intubated. The tidal volume was set at $7 \mathrm{~mL} / \mathrm{kg}$, the respiratory rate at $10 / \mathrm{min}$, and the $\mathrm{O}_{2} /$ air mixture at an $\mathrm{FiO}_{2}$ of 0.5. Sampling tubes were connected with a Datex-Ohmeda S/5 compact monitor (GE Healthcare, Helsinki, Finland). It took approximately $20 \mathrm{~min}$ for the data on the $\mathrm{S} / 5$ compact monitor to stabilize.

\section{Measurements}

Blood samples were obtained before the induction of anesthesia and centrifuged at $150 \mathrm{~g}$ at $4{ }^{\circ} \mathrm{C}$ for $10 \mathrm{~min}$ (Table Top cooling centrifuge 2800, Kubota, Tokyo, Japan). The plasma and serum samples were stored at $-20{ }^{\circ} \mathrm{C}$ until analysis and were analyzed by a clinical laboratory testing company (SRL Inc., Tokyo, Japan). The respiratory quotient (RQ) and energy expenditure (EE) were measured by the $\mathrm{S} / 5$ compact monitor.

Participants completed a 100-mm Visual Analog Scale (VAS; 0, "not at all"; 100, "extreme") to measure subjective well-being upon entering the operating room. The variables examined were those measured in a previous study [6]. In addition, the Patient Health Questionnaire-9 (PHQ9), a multiple instrument for screening, diagnosing, monitoring, and measuring the severity of mental health, was administered. This tool rates the frequency of symptoms, which is then factored into the scoring severity index. The PHQ-9 is completed by the patients and scored by the clinician. The questions pertain to nine items: little interest or pleasure in doing things, feeling low, trouble falling asleep, feeling tired, poor appetite, feeling bad about oneself, trouble concentrating on things, moving or speaking slowly, and suicidal or self-harming thoughts $[16,17]$.

\section{Statistical analysis}

The size of the study was chosen to detect a difference in the concentration of ketone bodies. A previous study reported that the concentration of ketone bodies in volunteers who received preoperative oral carbohydrates decreased from $124 \pm 118$ to $22 \pm 4 \mathrm{mmol} / \mathrm{L}$ before the induction of anesthesia [15]. Therefore, the required number of patients in each group was 12, with an alpha of 0.05 and a power of $80 \%$ for ketone bodies (SPSS SamplePower, IBM Co., Armonk, NY, USA). Comparisons between groups were performed using Student's $t$ test or the Mann-Whitney $U$ test. A $P$ value of $<0.05$ was considered statistically significant.

\section{Results}

The mean age of the 24 patients (16 men, 8 women) was 43 (21-63) years. One ONS group patient was excluded because of failure to consume the carbohydrate drink (Fig. 2). The demographic characteristics (Table 2) and preoperative total fluid intake [control group: $450(250,750)$ mL, ONS group: $600(500,738) \mathrm{mL}, P=0.085$, median (25th, 75th percentile)] did not differ significantly between groups. Compared with the control group, the ONS group showed significantly lower serum free fatty acid (FFA) levels [control group: $828(729,1004) \mu \mathrm{Eq} / \mathrm{L}$, ONS group: $479(408,610) \mu \mathrm{Eq} / \mathrm{L}, P=0.0002$, median $(25$ th, 75 th percentile); Fig. 3a] and total ketone bodies [control group: $119(68,440) \mu \mathrm{mol} / \mathrm{L}$, ONS group: $40[27,64] \mu \mathrm{mol} / \mathrm{L}$, $P=0.037$, median (25th, 75th percentile); Fig. 3b].

The preoperative serum glucose, insulin, 3-methylhistidine (3-MH), creatinine ( $\mathrm{Cr}$ ), and acute-phase protein levels and inflammatory indexes are shown in Table 3. There was no significant difference in any of these parameters between the two groups. Whole body oxygen consumption, carbon dioxide production, and EE were similar between groups after intubation, although RQ was lower in the control group than in the ONS group (Table 4).

The preoperative VAS scores for anxiety, hunger, and thirst were higher in the control group than in the ONS group, with no differences in any other measure of subjective well-being between groups (Table 5). In addition, the PHQ-9 score was significantly lower in the ONS group than in the control group, indicating a better preoperative quality of life (QOL) in the former than in the latter (Fig. 4).

\section{Discussion}

The results of this study suggest that preoperative ONS intake decreases the levels of FFA and ketone bodies, thus attenuating lipid catabolism before surgery, with the decreased RQ in the control group supporting this fact. Furthermore, preoperative ONS intake resulted in improved well-being compared with complete fasting.

Beverages containing $12.6 \%$ carbohydrates, which are common preoperative supplements in Europe, are not available in Japan, so we used a readily available commercial drink (18\% carbohydrate and $2 \%$ arginine; Arginaid Water $\left.{ }^{\circledR}\right)$. Although some clinical studies report the benefits of $12.6 \%$ carbohydrate loading of $800 \mathrm{~mL}$ the evening before the surgery and $400 \mathrm{~mL} 2 \mathrm{~h}$ before the anesthesia $[10,11]$, there are few reports showing the benefit of preoperative $18 \%$ carbohydrates for preoperative conditions such as starvation, lipid catabolism, and patient's QOL. Because most Japanese patients find it hard to drink a high volume, a small size $(100 \mathrm{kcal} / 125 \mathrm{~mL} /$ package $)$ is suited to them [15].

The patients included in the present study represent those who are typically allowed to drink clear fluids up to $2 \mathrm{~h}$ before surgery, according to existing guidelines 


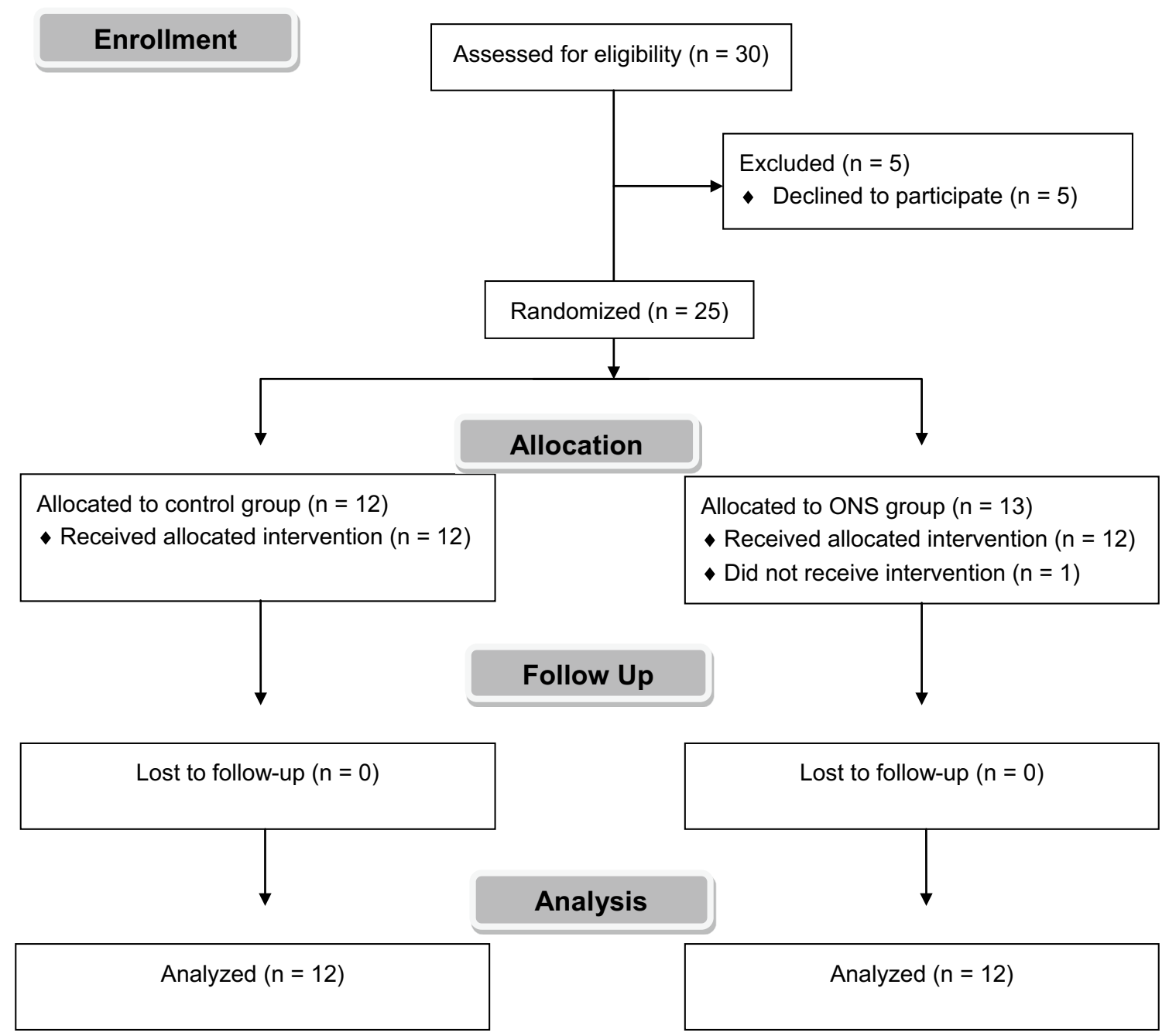

Fig. 2 CONSORT flow chart showing the selection process for patients

Table 2 Characteristics of patients at onset of surgery

\begin{tabular}{llll}
\hline & Control group & ONS group & $P$ value \\
\hline Age (years) & $43(21-61)$ & $43(29-63)$ & 0.723 \\
Male:female $(n)$ & $8: 4$ & $8: 4$ & \\
Baseline body mass index $(\mathrm{kg} /$ & $23.9 \pm 3.0$ & $23.2 \pm 3.3$ & 0.620 \\
$\left.\quad \mathrm{~m}^{2}\right)$ & & & \\
ASA Performance Status $(n)$ & & 5 & 0.705 \\
I & 4 & 7 & \\
II & 8 & & \\
Type of surgery $(n)$ & & 2 & \\
Salpingo-oophorectomy & 1 & 1 & \\
Partial mastectomy & 2 & 2 & \\
Endoscopic sinus surgery & 2 & 5 & \\
Skin surgery & 4 & 2 & \\
Arthroscopic surgery & 3 & & \\
\hline
\end{tabular}

Ranges in parentheses
[18-20]. There was no adverse event in the present study, but the rate of gastric emptying might be slower with clear fluid containing carbohydrate and amino acid [21]. These patients also exhibited an ASA PS of I-II; more than $85 \%$ patients in our hospital belong to this category. Therefore, preoperative preparation with ONS is potentially relevant and suitable for the majority of patients undergoing elective surgery.

A number of randomized controlled trials have examined whether preoperative carbohydrate intake results in improved postoperative recovery. However, several randomized trials including patients undergoing major abdominal $[7,8,12,22]$ or cardiac surgery [23] did not show improved clinical outcomes with preoperative carbohydrate intake. The median duration of hospital stay was 8 days in the carbohydrate group and 10 days in the placebo group in one study [7], while it was 17 and 16 days, respectively, 


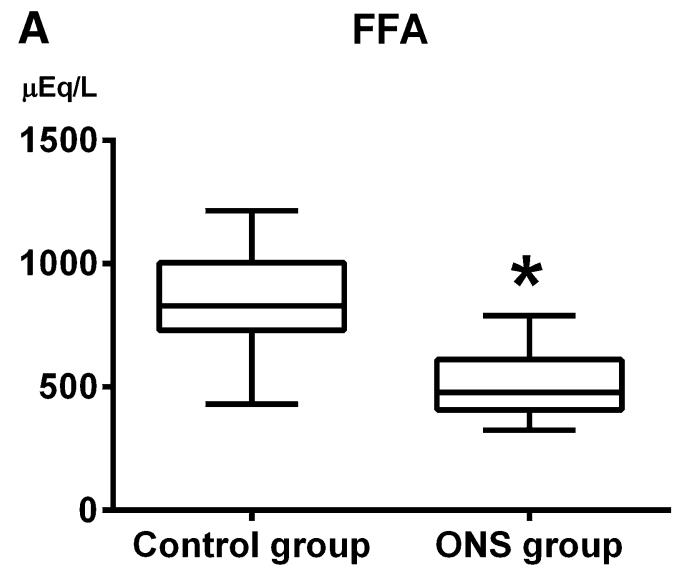

B Ketone bodies

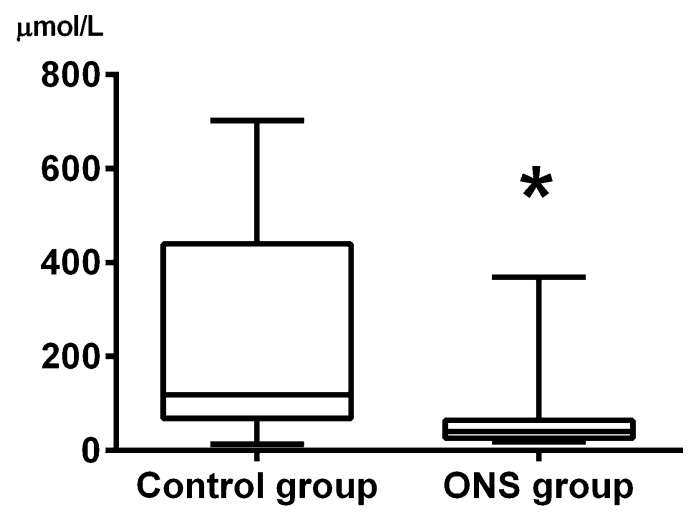

Fig. 3 Serum concentration of free fatty acids (a) and total ketone bodies (b) at the initiation of anesthesia. The boxes represent the 25 th to 75th percentiles, and the horizontal lines within the boxes represent median values. The whiskers represent the lowest and highest values in the 25 th percentile minus 1.5 interquartile range (IQR) and 75th percentile plus $1.5 \mathrm{IQR}$ regions, respectively. $* P<0.05$ compared with the control group

Table 3 Physiological data

\begin{tabular}{lccc}
\hline & Control group & ONS group & $P$ value \\
\hline Glucose $(\mathrm{mg} / \mathrm{dL})$ & $110 \pm 11$ & $107 \pm 9$ & 0.525 \\
Insulin $(\mu \mathrm{IU} / \mathrm{mL})$ & $3.4 \pm 2.4$ & $4.9 \pm 3.0$ & 0.199 \\
3-MH $(\mathrm{nmol} / \mathrm{mL})$ & $3.3 \pm 0.6$ & $3.1 \pm 1.1$ & 0.586 \\
Creatinine $(\mathrm{mg} / \mathrm{dL})$ & $0.58 \pm 0.17$ & $0.60 \pm 0.16$ & 0.757 \\
3-MH/creatinine ratio & $6.1 \pm 2.1$ & $5.2 \pm 1.9$ & 0.210 \\
Prealbumin $(\mathrm{g} / \mathrm{L})$ & $18.1 \pm 6.7$ & $19.1 \pm 4.1$ & 0.663 \\
CRP $(\mathrm{mg} / \mathrm{L})$ & $0.38 \pm 0.22$ & $0.33 \pm 0.18$ & 0.570 \\
Albumin $(\mathrm{g} / \mathrm{dL})$ & $3.1 \pm 0.5$ & $3.3 \pm 0.5$ & 0.271 \\
\hline
\end{tabular}

3-MH 3-methylhistidine, CRP C-reactive protein

in another study involving cardiac surgery patients [23]. In contrast, Noblett et al. [2] showed that the median hospital stay after colorectal surgery was significantly lower for patients who consumed carbohydrate drinks before surgery than for those who consumed water. Therefore, in the present study, the postoperative clinical outcomes (with or without ONS) were not assessed because the study focused on the potential clinical effects of ONS in the preoperative period. In addition, our preoperative data were not affected by anesthesia protocols (general/epidural anesthesia), perioperative fluid, surgical duration, surgical models (major, minor, or laparoscopic), and stress hormones and cytokines, the effects of which are likely to carry over to the postoperative phase. However, by way of precaution, a surgical model that induced minimal surgical stress (minor surgery) was selected to evaluate the effects of preoperative fasting compared with those of feeding per se, without the confounding effects of mental anxiety related to major surgery.

Food restriction is usually enforced from midnight before the day of surgery. We hypothesized that $200 \mathrm{kcal}$ $(250 \mathrm{~mL})$ ONS is appropriate as late evening intake. Glycogen stores deplete rapidly when patients are starved, thereby increasing the demand for amino acids for gluconeogenesis, rather than for tissue repair [24-26]. Furthermore, prolonged fasting has been demonstrated to decrease whole body protein synthesis, thus potentially accentuating protein catabolism after major surgery [27]. This is the most marked in the first few days following surgery and has been related to postoperative complications and length of hospital stay. In addition, investigators have targeted $2 \mathrm{~h}$ as the interval between carbohydrate ingestion and induction. Insulin levels have been reported to return to near-baseline values $2 \mathrm{~h}$ after oral carbohydrate intake, although insulin action is nevertheless enhanced beyond this period [28, 29]. In the present study, serum lipid catabolism (FFA and ketone bodies) was significantly lower in the ONS group than in the control group before surgical stress.

$\mathrm{RQ}$ is the indicator of which nutrient substrate is being metabolized to supply the body with energy. The RQ of the patients in ONS group was 0.85, implying that the administered ONS was used accurately for energy expenditure without exhaustion and glycogen storage in the liver was fully maintained during the preoperative period. The RQ of 0.78 in the control group indicated that fat was the predominant fuel source, suggesting that serum lipid catabolism might be occurring, whereas RQ levels in ONS group confirmed that lipid catabolism was inhibited (Fig. 3).

Studies have shown that formulae using acute-phase proteins may predict risks for hospitalized patients [13, 30, 31]; similar findings were observed in the two groups in the present study. C-reactive protein (CRP) is a positive acute-phase protein, the levels of which correlate well with the intensity of inflammation. On the other hand, decreased 
Table 4 Gaseous exchange and energy expenditure

\begin{tabular}{lccc}
\hline & Control group & ONS group & $P$ value \\
\hline $\begin{array}{l}\text { Oxygen consumption } \\
(\mathrm{mL} / \mathrm{min})\end{array}$ & $221 \pm 38$ & $209 \pm 33$ & 0.444 \\
$\begin{array}{l}\text { Carbon dioxide production } \\
(\mathrm{mL} / \mathrm{min})\end{array}$ & $171 \pm 35$ & $179 \pm 31$ & 0.587 \\
$\begin{array}{l}\text { Respiratory quotient } \\
\text { Energy expenditure (kcal/day) }\end{array}$ & $0.78 \pm 0.08$ & $0.85 \pm 0.08$ & 0.024 \\
\hline
\end{tabular}

Table 5 Preoperative visual analog scale score

\begin{tabular}{lccl}
\hline & Control group & ONS group & $P$ value \\
\hline Anxiety & $32(22,45)$ & $22(15,24)$ & 0.048 \\
Depression & $23(10,39)$ & $20(11,29)$ & 0.73 \\
Hunger & $43(30,59)$ & $13(3,20)$ & 0.001 \\
Malaise & $28(20,38)$ & $20(16,30)$ & 0.35 \\
Nausea & $0(0,9)$ & $0(0,9)$ & 0.84 \\
Thirst & $28(13,30)$ & $12(10,15)$ & 0.01 \\
\hline
\end{tabular}

Ranges in parentheses

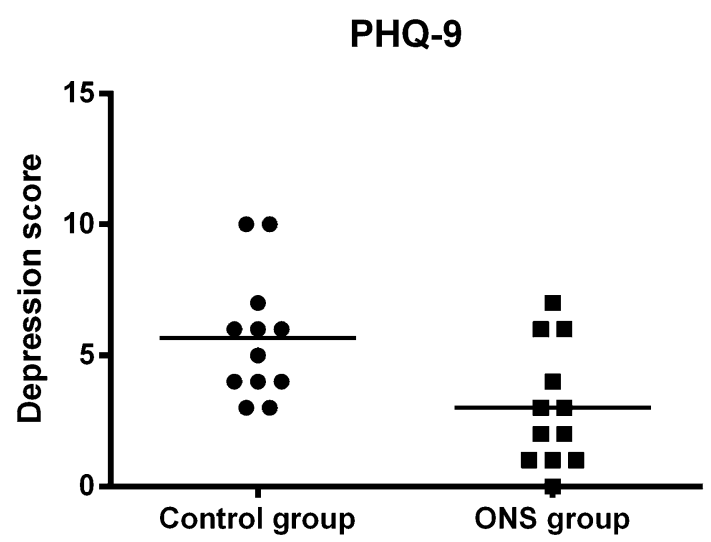

Fig. 4 Patient Health Questionnaire-9 (PHQ-9) scores. Values are reported as medians (center lines). The ONS group shows significantly lower scores $(P=0.013)$

levels of negative acute-phase proteins such as albumin and prealbumin after trauma are expected because of the inhibition of their synthesis by proinflammatory cytokines.

Our results have shown that preoperative ONS intake is beneficial for not only decreasing the fasting time but also improving the preoperative QOL. Preoperative anxiety, hunger, and thirst were attenuated in the ONS group, as opposed to the findings of Henriksen et al. [32]. However, our findings were consistent with those in other previous studies [6, 33, 34]. Furthermore, the ONS group showed lower PHQ-9 scores, indicating superior well-being and fewer general psychosomatic problems.
The commercial carbohydrate drinks with amino acid (Arginaid Water ${ }^{\circledR}$ ) used in the present study are common and frequently used as preoperative oral fluid supplements in Japan. The carbohydrate content is $18 \%$, much higher than in the fluid (preOp ${ }^{\circledR}$, Nutricia, Danone, Paris, France) most commonly used before surgery in Europe and other countries; however, there were no episodes of hyperglycemia or nausea/vomiting caused by the high carbohydrate content. Additionally, we could not determine the contribution of amino acid. Arginine has been reported to affect disposable insulin-mediated glucose [35] and to regulate metabolism of energy substrate [36]. In our study, however, there were no significant between-group differences in energy expenditure. Therefore, we could not explain the effects of $2 \%$ arginine on energy metabolism and lipid catabolism from our findings.

Other limitations of this study include the fact that the aforementioned beneficial effects cannot be solely attributed to one of the constituents of the drink (carbohydrate and arginine). Further studies would need to investigate the contributions of the different constituents of the drink to any potential beneficial effects observed. Furthermore, the present study did not measure the relative changes in insulin sensitivity, although the effects of preoperative fasting and carbohydrate drink intake on this parameter have been well characterized in previous studies [37, 38]. Furthermore, we did not include elderly patients, high-risk patients, or patients with an ASA PS of III or higher, and the safety and efficacy of preoperative ONS intake in these patients remain unclear. These patients had low BMI and low muscle mass, so that their glucose store should be less than in healthy subjects., More benefits of ONS loading were therefore expected. Further study is needed to evaluate the efficacy of ONS for these patients.

\section{Conclusions}

In conclusion, the results of this study suggest that preoperative ONS intake can improve lipid catabolism and starvation status before the induction of anesthesia, also resulting in better mental health compared with that after complete fasting.

Acknowledgments This work was supported by JSPS KAKENHI Grants nos. 15K16207 (RT), 16K16278 (KK) and The Japan Society for Clinical Anesthesia (The Kosaka Fund) (EH).

Open Access This article is distributed under the terms of the Creative Commons Attribution 4.0 International License (http://creativecommons.org/licenses/by/4.0/), which permits unrestricted use, distribution, and reproduction in any medium, provided you give appropriate credit to the original author(s) and the source, provide a link to the Creative Commons license, and indicate if changes were made. 


\section{References}

1. Fearon KC, Ljungqvist $\mathrm{O}$, Von Meyenfeldt $\mathrm{M}$, Revhaug A, Dejong CH, Lassen K, Nygren J, Hausel J, Soop M, Andersen J, Kehlet H. Enhanced recovery after surgery: a consensus review of clinical care for patients undergoing colonic resection. Clin Nutr. 2005;24:466-77.

2. Noblett SE, Watson DS, Huong H, Davison B, Hainsworth PJ, Horgan AF. Pre-operative oral carbohydrate loading in colorectal surgery: a randomized controlled trial. Colorectal Dis. 2006;8:563-9.

3. Botella-Carretero JI, Iglesias B, Balsa JA, Arrieta F, Zamarron I, Vazquez C. Perioperative oral nutritional supplements in normally or mildly undernourished geriatric patients submitted to surgery for hip fracture: a randomized clinical trial. Clin Nutr. 2010;29:574-9.

4. Nygren J, Soop M, Thorell A, Efendic S, Nair KS, Ljungqvist O. Preoperative oral carbohydrate administration reduces postoperative insulin resistance. Clin Nutr. 1998;17:65-71.

5. Nygren J, Soop M, Thorell A, Sree Nair K, Ljungqvist O. Preoperative oral carbohydrates and postoperative insulin resistance. Clin Nutr. 1999;18:117-20.

6. Hausel J, Nygren J, Lagerkranser M, Hellstrom PM, Hammarqvist F, Almstrom C, Lindh A, Thorell A, Ljungqvist O. A carbohydrate-rich drink reduces preoperative discomfort in elective surgery patients. Anesth Analg. 2001;93:1344-50.

7. Yuill KA, Richardson RA, Davidson HI, Garden OJ, Parks RW. The administration of an oral carbohydrate-containing fluid prior to major elective upper-gastrointestinal surgery preserves skeletal muscle mass postoperatively - a randomised clinical trial. Clin Nutr. 2005;24:32-7.

8. Mathur S, Plank LD, McCall JL, Shapkov P, Mcllroy K, Gillanders LK, Merrie AE, Torrie JJ, Pugh F, Koea JB, Bissett IP, Parry BR. Randomized controlled trial of preoperative oral carbohydrate treatment in major abdominal surgery. Br J Surg. 2010;97:485-94.

9. Jarvela K, Maaranen P, Sisto T. Pre-operative oral carbohydrate treatment before coronary artery bypass surgery. Acta Anaesthesiol Scand. 2008;52:793-7.

10. Helminen H, Viitanen H, Sajanti J. Effect of preoperative intravenous carbohydrate loading on preoperative discomfort in elective surgery patients. Eur J Anaesthesiol. 2009;26:123-7.

11. Can MF, Yagci G, Dag B, Ozturk E, Gorgulu S, Simsek A, Tufan T. Preoperative administration of oral carbohydrate-rich solutions: comparison of glucometabolic responses and tolerability between patients with and without insulin resistance. Nutrition. 2009;25:72-7.

12. Hausel J, Nygren J, Thorell A, Lagerkranser M, Ljungqvist O. Randomized clinical trial of the effects of oral preoperative carbohydrates on postoperative nausea and vomiting after laparoscopic cholecystectomy. Br J Surg. 2005;92:415-21.

13. Perrone F, da Silva-Filho AC, Adorno IF, Anabuki NT, Leal FS, Colombo T, da Silva BD, Dock-Nascimento DB, Damiao A, de Aguilar-Nascimento JE. Effects of preoperative feeding with a whey protein plus carbohydrate drink on the acute phase response and insulin resistance. A randomized trial. Nutr J. 2011;10:66.

14. Pexe-Machado PA, de Oliveira BD, Dock-Nascimento DB, de Aguilar-Nascimento JE. Shrinking preoperative fast time with maltodextrin and protein hydrolysate in gastrointestinal resections due to cancer. Nutrition. 2013;29:1054-9.

15. Tamura T, Yatabe T, Kitagawa H, Yamashita K, Hanazaki K, Yokoyama M. Oral carbohydrate loading with $18 \%$ carbohydrate beverage alleviates insulin resistance. Asia Pac J Clin Nutr. 2013;22:48-53.
16. Schonberger RB, Feinleib J, Holt N, Dai F, Brandt C, Burg MM. Preoperative depression symptom severity and its impact on adherence to preoperative beta-blocker therapy. J Cardiothorac Vasc Anesth. 2014;28:1467-73.

17. Jiang M, Wang MH, Wang XB, Liu L, Wu JL, Yang XL, Liu XR, Zhang CX. Effect of intraoperative application of ketamine on postoperative depressed mood in patients undergoing elective orthopedic surgery. J Anesth. 2016;30(2):232-237.

18. American Society of Anesthesiologists C. Practice guidelines for preoperative fasting and the use of pharmacologic agents to reduce the risk of pulmonary aspiration: application to healthy patients undergoing elective procedures: an updated report by the American Society of Anesthesiologists Committee on Standards and Practice Parameters. Anesthesiology. 2011;114:495-511.

19. Smith I, Kranke P, Murat I, Smith A, O'Sullivan G, Soreide E, Spies C, in't Veld B, European Society of A. Perioperative fasting in adults and children: guidelines from the European Society of Anaesthesiology. Eur J Anaesthesiol. 2011;28:556-69.

20. Mortensen K, Nilsson M, Slim K, Schafer M, Mariette C, Braga M, Carli F, Demartines N, Griffin SM, Lassen K, Enhanced Recovery After Surgery G. Consensus guidelines for enhanced recovery after gastrectomy: Enhanced Recovery After Surgery (ERAS(R)) Society recommendations. Br J Surg. 2014;101:1209-29.

21. Lobo DN, Hendry PO, Rodrigues G, Marciani L, Totman JJ, Wright JW, Preston T, Gowland P, Spiller RC, Fearon KC. Gastric emptying of three liquid oral preoperative metabolic preconditioning regimens measured by magnetic resonance imaging in healthy adult volunteers: a randomised double-blind, crossover study. Clin Nutr. 2009;28:636-41.

22. Bisgaard T, Kristiansen VB, Hjortso NC, Jacobsen LS, Rosenberg J, Kehlet H. Randomized clinical trial comparing an oral carbohydrate beverage with placebo before laparoscopic cholecystectomy. Br J Surg. 2004;91:151-8.

23. Breuer JP, von Dossow V, von Heymann C, Griesbach M, von Schickfus M, Mackh E, Hacker C, Elgeti U, Konertz W, Wernecke KD, Spies CD. Preoperative oral carbohydrate administration to ASA III-IV patients undergoing elective cardiac surgery. Anesth Analg. 2006;103:1099-108.

24. Dahn MS, Mitchell RA, Lange MP, Smith S, Jacobs LA. Hepatic metabolic response to injury and sepsis. Surgery. 1995;117:520-30.

25. Yamanaka-Okumura H, Nakamura T, Takeuchi H, Miyake H, Katayama T, Arai H, Taketani Y, Fujii M, Shimada M, Takeda E. Effect of late evening snack with rice ball on energy metabolism in liver cirrhosis. Eur J Clin Nutr. 2006;60:1067-72.

26. Nakaya Y, Shimohata T, Haraguchi S, Nakao T, Minaguchi J, Sumitani H, Harada N, Sakaue H. Severe catabolic state after an overnight fast in patients with chronic renal failure. Nutrition. 2011;27:329-32.

27. Rennie MJ, Edwards RH, Halliday D, Matthews DE, Wolman SL, Millward DJ. Muscle protein synthesis measured by stable isotope techniques in man: the effects of feeding and fasting. Clin Sci (Lond). 1982;63:519-23.

28. Nygren J, Thorell A, Jacobsson H, Larsson S, Schnell PO, Hylen L, Ljungqvist O. Preoperative gastric emptying. Effects of anxiety and oral carbohydrate administration. Ann Surg. 1995;222:728-34.

29. Svanfeldt M, Thorell A, Hausel J, Soop M, Nygren J, Ljungqvist O. Effect of "preoperative" oral carbohydrate treatment on insulin action-a randomised cross-over unblinded study in healthy subjects. Clin Nutr. 2005;24:815-21.

30. Ingenbleek Y, Carpentier YA. A prognostic inflammatory and nutritional index scoring critically ill patients. Int J Vitam Nutr Res. 1985;55:91-101. 
31. Vehe KL, Brown RO, Kuhl DA, Boucher BA, Luther RW, Kudsk KA. The prognostic inflammatory and nutritional index in traumatized patients receiving enteral nutrition support. J Am Coll Nutr. 1991;10:355-63.

32. Henriksen MG, Hessov I, Dela F, Hansen HV, Haraldsted V, Rodt SA. Effects of preoperative oral carbohydrates and peptides on postoperative endocrine response, mobilization, nutrition and muscle function in abdominal surgery. Acta Anaesthesiol Scand. 2003;47:191-9.

33. Wang ZG, Wang Q, Wang WJ, Qin HL. Randomized clinical trial to compare the effects of preoperative oral carbohydrate versus placebo on insulin resistance after colorectal surgery. Br J Surg. 2010;97:317-27.

34. Tran S, Wolever TM, Errett LE, Ahn H, Mazer CD, Keith M. Preoperative carbohydrate loading in patients undergoing coronary artery bypass or spinal surgery. Anesth Analg. 2013;117:305-13.
35. Paolisso G, Tagliamonte MR, Marfella R, Verrazzo G, D’Onofrio F, Giugliano D. L-Arginine but not D-arginine stimulates insulinmediated glucose uptake. Metabolism. 1997;46:1068-73.

36. McKnight JR, Satterfield MC, Jobgen WS, Smith SB, Spencer TE, Meininger CJ, McNeal CJ, Wu G. Beneficial effects of L-arginine on reducing obesity: potential mechanisms and important implications for human health. Amino Acids. 2010;39:349-57.

37. Thorell A, Nygren J, Hirshman MF, Hayashi T, Nair KS, Horton ES, Goodyear LJ, Ljungqvist O. Surgery-induced insulin resistance in human patients: relation to glucose transport and utilization. Am J Physiol. 1999;276:E754-61.

38. Awad S, Constantin-Teodosiu D, Macdonald IA, Lobo DN. Short-term starvation and mitochondrial dysfunction-a possible mechanism leading to postoperative insulin resistance. Clin Nutr. 2009;28:497-509. 